\title{
ESTUDOS DE PROTEÇÃo DA CÉLULA DE SACCHAROMYCES CEREVISIAE PARA UTILIZAÇÃo EM REAÇÕES DE REDUÇÃO EM MEIO ORGÂNICO
}

\author{
Maria da Graça Nascimento*, Sandra Patricia Zanotto e Sílvia Pedroso Melegari \\ Departamento de Química, Universidade Federal de Santa Catarina, CP 476, 88040-900 Florianópolis - SC \\ Paulo J. S. Moran \\ Instituto de Química, Universidade Estadual de Campinas, CP 6154, 13183-970 Campinas - SP
}

Recebido em 16/7/01; aceito em 3/10/01

\begin{abstract}
PROTECTION STUDIES OF SACCHAROMYCES CEREVISIAE CELLS FOR THE USE IN REDUCTION REACTIONS IN ORGANIC MEDIA. New methodologies for protection of Saccharomyces cerevisiae (FP) cells when supported in montmorillonite $\mathrm{K} 10$ (K10), recovered or not with gelatin $(\mathrm{G})$ and in the presence or absence of sucrose (S) are presented. These systems were used for the enantioselective reduction of ethyl acetoacetate and $\alpha$-chloroacetophenone in hexane, under FP/K10/G/S and FP/S at $20^{\circ} \mathrm{C}$ during 24 hours, affording $S$-(+)-ethyl-3-hydroxybutanoate in $100 \%$ conversion and $99 \%$ ee, and $R$-(-)-2-chloro-1phenylethanol $79 \%$ and $78 \%$ ee at 20 and $30{ }^{\circ} \mathrm{C}$, respectivelly.
\end{abstract}

Keywords: biotransformations; baker's yeast; enantioselective reduction.

\section{INTRODUÇÃO}

Atualmente, a importância na produção de substâncias opticamente puras é um capítulo de destaque nos setores acadêmicos e industriais, preocupados com a pesquisa e o desenvolvimento de novos processos. Quando os químicos sintetizam produtos naturais e desenham novos alvos, a pureza enantiomérica dos produtos, $\mathrm{e}$ sua relação com as propriedades biológicas, é um tema de permanente discussão ${ }^{1}$.

O crescente interesse por esse tipo de síntese promoveu um grande desenvolvimento na biocatálise. Contudo, ainda que a habilidade das enzimas e dos microorganismos para agir como catalisadores quirais específicos, seja conhecida, principalmente pela indústria farmacêutica, os procedimentos bioquímicos apenas tornaram-se aceitos como técnicas experimentais rotineiras em laboratórios de síntese orgânica nos últimos anos ${ }^{2}$.

Portanto, a habilidade de conduzir transformações químicas que são impossíveis ou impraticáveis de outra forma, especialmente na área de obtenção de compostos enantiomericamente puros; aliada à necessidade de mudar os catalisadores hoje existentes (geralmente constituídos de metais pesados ou de transição, altamente nocivos ao ambiente) por catálises "ambientalmente corretas", tornam o uso de biocatalisadores um dos maiores desafios da síntese orgânica na atualidade ${ }^{3-7}$.

A possibilidade de atuar na catálise de reações em meios quase anidros ou micro-aquosos expandiu largamente o potencial de aplicações de enzimas e microrganismos em síntese orgânica. A ausência de fase aquosa contínua em torno do biocatalisador torna possível sua interação direta com o solvente, promovendo alterações de estabilidade, atividade e estereosseletividade ${ }^{8,9}$. Além disso, nestas condições as hidrolases, por exemplo, são capazes de catalisar reações de esterificações e transesterificações com altos rendimentos.

As enzimas e os microrganismos estão sujeitos à inativação por fatores químicos, físicos ou biológicos, como decorrência da estocagem ou mesmo durante o uso. Há assim, uma necessidade de estabilizar estes biocatalisadores, como meio de evitar a inativação para uso em meio orgânico. Portanto, para a manutenção da atividade catalítica e do potencial de estereosseletividade, é necessário o desenvolvimento de métodos preventivos específicos.

Neste sentido, a técnica de imobilização em diferentes suportes é uma das mais utilizadas na biocatálise, sendo bastante aplicada para mediar reações de interesse sintético em solventes orgânicos ${ }^{10,11}$. A imobilização do biocatalisador em um suporte, sem prejuízo de sua atividade por um razoável período de tempo, pode assegurar sua repetida utilização ou mesmo possibilitar o uso em reatores contínuos, resultando em economia nos processos industriais. Assim, de modo geral, a utilização de materiais imobilizados além de diminuir o custo por análise, aumenta a rapidez e a exatidão do processo. Nos processos sintéticos, a facilidade de extração dos produtos do meio reacional aliada à estabilidade do biocatalisador em reações de longa duração (ou com substratos nocivos) são de grande interesse nas biotransformações.

A célula de Saccharomyces cerevisiae, que utiliza glicose ou sacarose como fonte de energia, é um dos biocatalisadores mais versáteis e baratos. A facilidade de manuseio, que não requer nenhum cuidado especial, o faz alvo de escolha quando se deseja conduzir reações de oxidação-redução. É preferencialmente utilizado na forma de célula inteira, ao invés de enzimas isoladas, evitando dessa forma, o problema da dificuldade de reciclar o cofator, um passo necessário quando se usa a enzima pura. As células inteiras apresentam uma grande variedade de atividades enzimáticas. Por isso, o maior problema encontrado neste tipo de biocatálise é a baixa seletividade, devido à ação simultânea das várias enzimas presentes, que geralmente apresentam diferentes cinéticas e velocidades de conversão para um mesmo substrato ${ }^{12}$. No entanto, quando o processo não é satisfatoriamente seletivo, modificações simples nas condições experimentais podem ser realizadas no sentido de influenciar tanto a estereoquímica como a enantiosseletividade ${ }^{13}$. Algumas das modificações mais comuns são o uso de solventes orgânicos, a adição de inibidores ou co-substratos ${ }^{14,15}$ e as técnicas de imobilização ${ }^{11,16,17}$, entre outras ${ }^{2}$.

Algumas enzimas hidrolíticas, como as lipases e as proteases, são reconhecidamente retentoras da atividade catalítica em solventes

*e-mail: graca@qmc.ufsc.br 
orgânicos. Entretanto, as desidrogenases e redutases são diferentes das hidrolíticas e requerem quantidades estequiométricas das coenzimas NADH ou NADPH. Devido ao alto custo, essas coenzimas são normalmente recicladas. A utilização de células inteiras é uma maneira de resolver o problema de reciclagem da coenzima, porém os solventes orgânicos freqüentemente acarretam danos na membrana hidrofóbica da célula do microorganismo.

O uso de solventes orgânicos é vantajoso devido à solubilidade do substrato e à capacidade que possuem em impedir as reações laterais pela água. Além disso, a seletividade da enzima do fermento pelo substrato pode mudar em meio orgânico. A adição de pequenas quantidades de água é necessária sob tais condições de reação, para que a enzima se mantenha cataliticamente ativa ${ }^{8}$. Já o isolamento de produtos de meios não aquosos é bem mais fácil do que de meios aquosos, sendo este mais um grande beneficio ${ }^{18,19}$.

Nakamura e col. realizaram os primeiros estudos de redução de $\alpha$-ceto ésteres com fermento de pão (FP) seco não imobilizado em benzeno e hexano. Observaram que a utilização controlada de gotas de água $\left(0,4\right.$ equivalentes; $\left.\mathrm{mL} \mathrm{H}_{2} \mathrm{O} / \mathrm{g} \mathrm{FP}\right)$ no sistema é indispensável para promover a redução. Já o excesso de água suprime radicalmente a redução ${ }^{18}$. Smallridge e col. em 1994, estenderam as investigações na redução de $\beta$-cetoésteres com FP em uma série de solventes polares e não polares, num estudo que foi completado verificandose o efeito da influência da água na reatividade ${ }^{20}$. Estes resultados demonstraram clara e seguramente que a reação é afetada tanto pela natureza do solvente, quanto pela razão água/fermento (independente da razão água/solvente). Também foi constatado, que a redução do acetoacetato de etila (2) com FP em solvente orgânico resultou na formação exclusiva de (S)-3-hidroxibutirato de etila com ee de $96 \%$, para todas as condições de reação empregadas. Estes resultados contrastam com os obtidos por Nakamura e col. ${ }^{21}$, onde a redução de $\alpha$ cetoésteres com FP em água formou o enantiômero- $S$, enquanto que em solvente orgânico obteve-se o enantiômero- $R^{20}$.

Rotthaus e col. estudaram a redução de $\alpha$ - e $\beta$-cetoésteres (1-5) com FP em hexano, tolueno, éter dietílico e acetato de etila ${ }^{8}$. As reações de redução em solventes orgânicos ocorreram preferencialmente em tolueno e hexano, sendo que os melhores resultados foram obtidos para o composto 1 em hexano, e para o 2 em tolueno. A tendência do ee na redução dos compostos $\mathbf{1}$ a $\mathbf{5}$, em solvente orgânico, sugere que o aumento do comprimento da cadeia no lado ceto do substrato está relacionada diretamente ao aumento da percentagem de produto com a configuração $R$. Estes resultados estão de acordo com a regra de Prelog 22 .

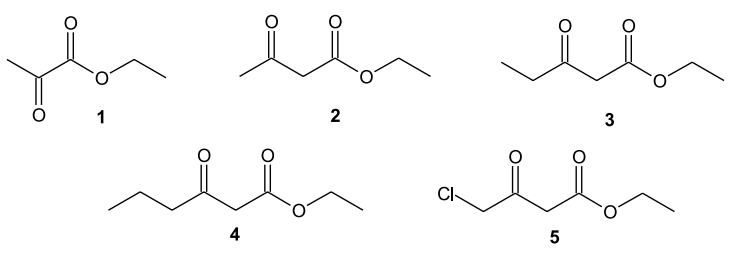

Uma série de $(S)$ - $\beta$-hidroxiésteres foi preparada por Smallridge e col. usando fermento de pão como mediador da redução de $\beta$-oxoésteres em éter de petróleo $\left(40-60{ }^{\circ} \mathrm{C}\right)$. Os produtos foram obtidos com rendimentos entre 56 e $96 \%$, e alto grau de estereosseletividade (94-99\% ee). Estes resultados são superiores aos descritos na literatura quando as mesmas reações foram conduzidas em fase aquosa ${ }^{23}$ (Esquema1).

Recentemente Kanda e col. verificaram que o duplo entrapeamento da célula do fermento de pão com alginato de cálcio e prépolímero uretano (PU-6), torna-a suficientemente protegida do solvente orgânico, para repetidas reduções estereosseletivas, em reações de longa duração ${ }^{24}$.

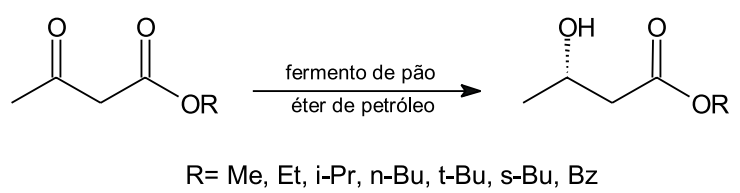

Esquema 1

Uma das contribuições mais recentes, para o avanço dos estudos de redução mediada por FP em meio orgânico, foi realizada por Smallridge e col. Eles observaram que a atividade do fermento decresce após 24 horas de exposição a solventes orgânicos; e investigaram os fatores associados com esta redução da atividade ${ }^{25}$. Num estudo complementar, a facilidade de redução de $\beta$-ceto ésteres foi relacionada à variação do tamanho da cadeia carbônica ligada ao carbono ceto. A proximidade dos grupos mais volumosos à carbonila proporciona uma redução mais rápida. Finalmente, as $\beta$-ceto amidas são consideravelmente menos reativas que os correspondentes $\beta$-ceto ésteres $^{26}$. Em outro trabalho, verificou-se que grupos metilênicos conjugados com carbonilas e nitrilas, podem ser reduzidos com um alto grau de estereosseletividade e bons rendimentos ${ }^{27}$.

Em contribuição a estes estudos, neste trabalho foram investigadas várias metodologias para a proteção de células de Saccharomyces cerevisiae, visando a sua utilização em reações de redução de compostos carbonílicos em meio orgânico. A obtenção estereosseletiva de uma haloidrina foi testada juntamente com a facilidade de sua extração do meio reacional, para verificar a eficiência dos sistemas de proteção em estudo, quando se tem um substrato tóxico para o FP, como a $\alpha$-cloroacetofenona.

\section{PARTE EXPERIMENTAL}

\section{Materiais}

Os espectros RMN ${ }^{1} \mathrm{H}$ foram obtidos em um espectrômetro da Bruker AC $200 \mathrm{MHz}$. Os cromatogramas e espectros de massas foram obtidos em um cromatógrafo a gás GC-MS-QP5000 da Shimadzu, equipado com coluna da Supelco (Simplicity 1 Capillary Columm, $30 \mathrm{~m}$ x 0,25 mm x $025 \mu \mathrm{m}, \mathrm{N}^{\circ}$ 11702-05B). As determinações dos excessos enantioméricos foram realizadas em GC-14B Shimadzu, com coluna quiral CHROMPACK (chirasil - DEX CB $25 \mathrm{~m} \times 0,25)$. As rotações ópticas específicas foram medidas em um Polarímetro - Polartronic E. Fermento de pão (FP) biológico, instantâneo e seco (Saccharomyces cerevisiae, EMULZINT - LTDA da Bélgica), foi utilizado como biocatalisador. As células foram imobilizadas em montmorilonita K10 (K10) (Aldrich Chemical Co.) e revestidas com gel de gelatina (G) (SIGMA G2500, Tipo A). Acetoacetato de etila e $\alpha$-cloroacetofenona (Carlo Erba) foram utilizados sem purificação. Os produtos racêmicos utilizados como padrões para CG quiral ( \pm )-3-hidroxibutanoato de etila e ( \pm )-2-cloro1-fenil-etanol foram obtidos através da reação de redução com $\mathrm{NaBH}_{4}$ (Aldrich Chemical Co. $)^{28}$. O hexano (Grupo Química) foi purificado através de lavagem com ácido sulfúrico e neutralização, seguida de destilação (p.e. exp $=68^{\circ} \mathrm{C}$; p.e. lit. $\left.=69^{\circ} \mathrm{C}\right)^{29}$. A pré-purificação dos produtos obtidos foi realizada por coluna cromatográfica de sílica (Carlo Erba, 0,05-0,20 mm)

\section{Procedimento geral para a adsorção e recobrimento}

Uma suspensão com 2,0 g de FP belga seco e 6,0 g de montmorilonita $\mathrm{K} 10$, em aproximadamente $100 \mathrm{~mL}$ de água foi agitada vigorosamente por uma noite, à temperatura ambiente. A mistu- 
ra de FP/K10 foi então filtrada a vácuo, seca sob corrente de ar e triturada até resultar em partículas finas. Uma solução de $0,5 \mathrm{~g}$ de gelatina em $5,0 \mathrm{~mL}$ de água foi aquecida até $50{ }^{\circ} \mathrm{C}$, e em seguida, resfriada a $\pm 30{ }^{\circ} \mathrm{C}$, e misturada ao sólido $\mathrm{FP} / \mathrm{K} 10$. A mistura FP/ $\mathrm{K} 10 / \mathrm{G}$ resultante foi seca sob corrente de ar.

\section{Procedimento geral para biotransformação}

Em um erlenmeyer foram colocados $100 \mathrm{~mL}$ de hexano, e em seguida o biocatalisador foi adicionado, sob agitação magnética. Água ou solução de sacarose, foi gotejada lentamente sob agitação magnética vigorosa. Após a adição de $0,2 \mathrm{~mL}$ (1,57 mmoles) de acetoacetato de etila, a mistura reacional foi mantida sob agitação em um banho termostatizado tipo Dubnoff a 20 e $30{ }^{\circ} \mathrm{C}$ por $24 \mathrm{~h}$ (Tabela 1).

\section{Procedimento para reutilização do biocatalisador}

Após o término de cada reação, o sobrenadante foi filtrado a vácuo lavado com hexano $(3$ x 30,0 mL), ressuspendido em $100 \mathrm{~mL}$ de hexano e novamente $0,2 \mathrm{~g}$ (1,57 mmoles) de acetoacetato de etila foram adicionados. A mistura reacional foi mantida sob agitação em um banho termostatizado tipo Dubnoff a 20 e $30{ }^{\circ} \mathrm{C}$ por $24 \mathrm{~h}$ (Tabela 1).

\section{Procedimento para as reações controle}

As reações de controle foram realizadas, utilizando FP sem qualquer imobilização. O procedimento geral para estas reações foi a adição de 2,0 g de FP em $50 \mathrm{~mL}$ de hexano com 0,2 $\mathrm{mL}$ (1,57 mmoles) de acetoacetato de etila (Tabela 1, Entrada 1).

\section{Procedimento geral para a reação de redução da $\alpha$-cloroacetofenona}

As metodologias de adsorção e recobrimento já descritas foram utilizadas, porém, verificou-se a necessidade de se usar o dobro das quantidades acima descritas. Os melhores resultados foram obtidos para a reação modelo com os sistemas FP/K10/G/S e FP/S. Estes dois sistemas determinaram, portanto, os ensaios de redução da $\alpha$ cloroacetofenona em diferentes tempos (24, 48 e 72 horas) e temperaturas $\left(20 \mathrm{e} 30^{\circ} \mathrm{C}\right)$. As estereosseletividades foram avaliadas nestas condições. Para cada sistema (FP/K10/G e FP), foram adicionados $50 \mathrm{~mL}$ de hexano e estes submetidos à agitação magnética. Com uma bomba peristáltica e agitação magnética vigorosa, foram adicionadas vagarosamente uma solução de $0,32 \mathrm{~g}$ de sacarose em 3,2 $\mathrm{mL}$ de água em cada um dos sistemas. Sob agitação tipo Dubnoff a
20 ou $30{ }^{\circ} \mathrm{C}$, foram adicionados $0,2 \mathrm{~g}$ (1,3 mmoles) de a-cloroacetofenona. Após 24, 48 e 72 h de reação, o meio reacional foi separado do suporte por filtração, e pré-purificado em uma coluna cromatográfica de sílica para eliminar partículas provenientes do FP, o solvente foi evaporado. A análise da mistura reacional foi realizada por CG, com uma coluna quiral. A reutilização dos dois sistemas foi testada, adicionando-se novamente $0,2 \mathrm{~g}$ (1,3 mmoles) de $\alpha$ cloroacetofenona e $50 \mathrm{~mL}$ de hexano; após a filtragem a vácuo do sobrenadante e a lavagem do suporte com hexano $(3 \times 30,0 \mathrm{~mL})$ sob agitação magnética.

\section{RESULTADOS E DISCUSSÃO}

A reação de redução do acetoacetato de etila foi utilizada como um modelo em todos os estudos dos processos de imobilização e recobrimento, com a finalidade de padronizar uma metodologia para outros substratos. Muitos detalhes desta reação modelo são bem conhecidos, principalmente considerando-se que o valor do excesso enantiomérico do álcool produzido pode ser facilmente monitorado por cromatografia gasosa com uma coluna com fase estacionária quiral. Além disto, $\beta$-hidroxiésteres enantiomericamente puros, tem sido usados como materiais de partida em sínteses orgânicas (Esquema 2$)^{26}$.

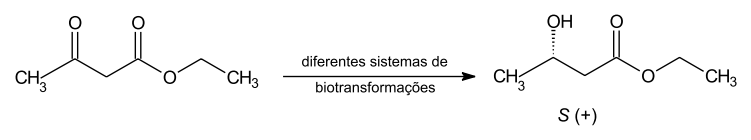

Esquema 2

Estudos anteriores realizados por Moran e col..$^{30}$ demonstraram que a relação ideal de FP fresco (contém 70\% de umidade) e K10 é de 1:1. Neste trabalho foi usado o FP desidratado e a proporção biocatalisador : suporte foi 3:1. Não foi observada qualquer diferença na obtenção do produto final, após a hidratação do FP antes de sua adsorção em K10, com solução de $\mathrm{KCl}(2 \%)$ e sacarose (razão de sacarose/ FP 1:1).

Sabe-se que a utilização de quantidades de água (entre 0,2 a $1,2 \mathrm{~mL}$ de água por grama de fermento) adicionadas ao meio reacional é indispensável para que ocorra a reação ${ }^{18,20,21,26}$. Foram realizados testes para estabelecer a quantidade ideal de água, dentro da faixa estipulada pela literatura como aceitável, que pode ser adicionada ao meio sem alterar a morfologia dos sistemas em estudo (FP, FP/K10, $\mathrm{FP} / \mathrm{G}, \mathrm{FP} / \mathrm{K} 10 / \mathrm{G})$. O valor máximo de água foi de $0,8 \mathrm{~mL}$ por grama de FP, quantidade esta que ainda preserva a área superficial dos sistemas de ser diminuída por aglutinação.

Tabela 1. Diferentes condições experimentais empregadas nas reações de redução de acetoacetato de etila mediadas por FP, em hexano ${ }^{a}$

\begin{tabular}{|c|c|c|c|c|c|c|}
\hline Entradas & Sistemas & $\mathrm{H}_{2} \mathrm{O}(\mathrm{mL})$ & $\mathrm{FP}^{\mathrm{b}}(\mathrm{g})$ & $\mathrm{K} 10^{\mathrm{c}}(\mathrm{g})$ & $\mathrm{G}^{\mathrm{d}}(\mathrm{g} / \mathrm{mL})$ & Sacarose $(\mathrm{S})(\mathrm{g})$ \\
\hline 1 & $\mathrm{FP}$ & 1,6 & 2,0 & _ & _ & - \\
\hline 2 & $\mathrm{FP} / \mathrm{S}$ & 1,6 & 2,0 & - & - & $0, \overline{16}$ \\
\hline 3 & $\mathrm{FP} / \mathrm{G}$ & 1,6 & 2,0 & - & 0,1 & - \\
\hline 4 & $\mathrm{FP} / \mathrm{G} / \mathrm{S}$ & 1,6 & 2,0 & - & 0,1 & 0,16 \\
\hline 5 & FP/K10 & 1,6 & 2,0 & 6,0 & - & - \\
\hline 6 & $\mathrm{FP} / \mathrm{K} 10 / \mathrm{S}$ & 1,6 & 2,0 & 6,0 & - & 0,16 \\
\hline 7 & FP/K10/G & 1,6 & 2,0 & 6,0 & $\overline{0,1}$ & - \\
\hline 8 & $\mathrm{FP} / \mathrm{K} 10 / \mathrm{G} / \mathrm{S}$ & 1,6 & 2,0 & 6,0 & 0,1 & 0,16 \\
\hline
\end{tabular}

a) $\mathrm{O}$ meio reacional sofreu agitação tipo Dubnoff, e os experimentos foram realizados em duplicatas para comparação dos resultados; b) FP = fermento de pão; c) $\mathrm{K} 10=$ montmorilonita $\mathrm{K}-10$; d) $\mathrm{G}=$ gelatina

Temperaturas: 20 e $30^{\circ} \mathrm{C}$ 
Conforme esperado, não houve formação de produto quando a reação foi realizada na presença de K10 sem a adição de FP. Verificou-se por CG-quiral, com os sistemas FP, FP/S e FP/K10/G/S a $20{ }^{\circ} \mathrm{C}$ que, após 24 h de reação obteve-se $100 \%$ de conversão (\%c) ao produto 3-hidroxibutanoato de etila. (Figura 1).

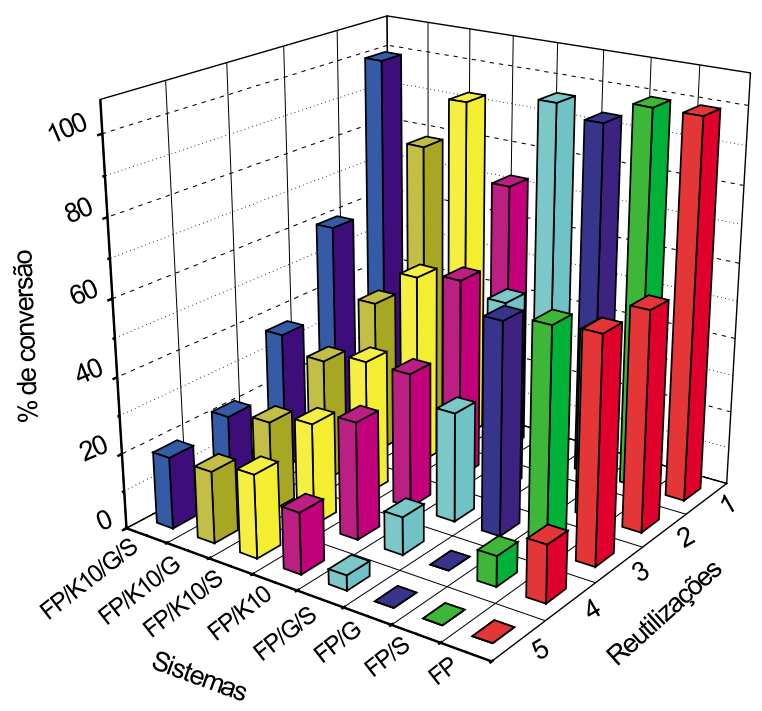

Figura 1. Porcentagem de conversão $(\%$ c) do acetoacetato de etila em (S)(+)-3-hidroxibutirato de etila mediada por FP em diferentes sistemas de imobilização e em função do número de reutilização, em hexano a $20{ }^{\circ} \mathrm{C}$.

Nas reações efetuadas a $30^{\circ} \mathrm{C}$, também foi obtido $100 \%$ de conversão para o produto utilizando os sistemas FP, FP/S e FP/K10/G/ S. Para o sistema FP o valor de \%c diminuiu para $7 \%$ na primeira reutilização. Com o sistema FP/K10/G/S, obteve-se o produto com $19 \%$ de conversão na primeira reutilização, mostrando uma modesta proteção para as células do FP. Após a primeira reação, todos os sistemas foram avaliados em até quatro reutilizações (Figura 2).

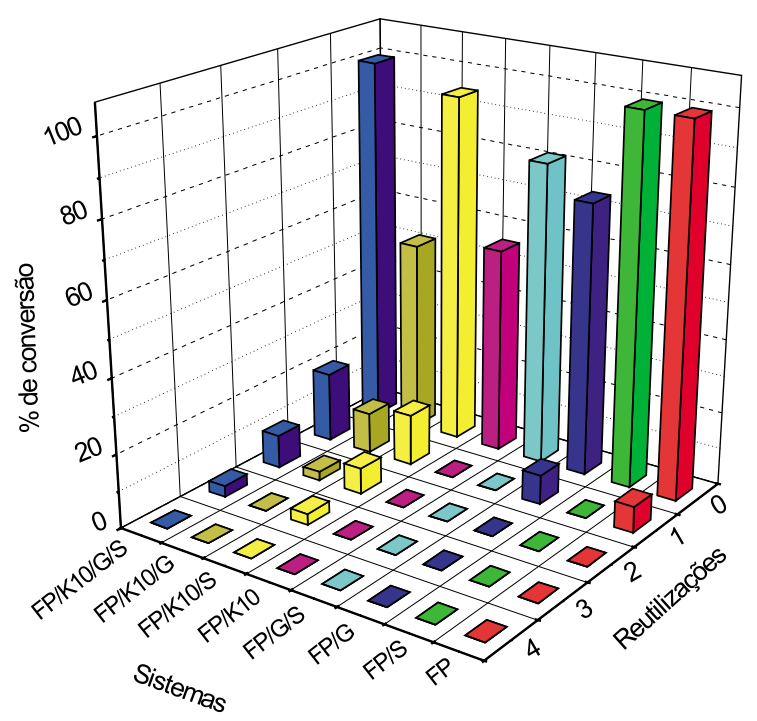

Figura 2. Porcentagem de conversão $(\%$ c) do acetoacetato de etila em (S)(+)-3-hidroxibutirato de etila mediada por FP em diferentes sistemas de imobilização e em função do número de reutilização, em hexano a $30^{\circ} \mathrm{C}$.
Através da análise das Figuras 1 e 2, pode-se verificar que a partir da segunda reutilização, ou seja, a terceira reação a que o sistema foi submetido, as áreas que correspondem aos produtos da reação diminuíram significativamente, principalmente à temperatura de $30{ }^{\circ} \mathrm{C}$. A temperatura exerce uma influência na desativação da enzima redutase do $\mathrm{FP}^{25}$. Como conseqüência, ocorreu a desativação da enzima após 24 h e obtiveram-se valores de conversão menores quando as reações foram realizadas a $30{ }^{\circ} \mathrm{C}$.

Os valores de ee, analisados por CG-quiral, foram para todos os sistemas superiores a 99\%. Para todos eles, apenas um dos enantiômeros foi detectado. As condições cromatográficas para a separação dos enantiômeros preestabelecidas e as medidas de rotação ótica $[\alpha]^{\mathrm{T}}$ indicaram a formação do $(S)$-(+)-3-hidroxibutanoato de etila puro de acordo com a literatura ${ }^{12,31}$.

Para os sistemas FP/K10 e FP/K10/G sem a adição de sacarose, a \%c diminuiu consideravelmente em relação aos mesmos sistemas com adição de sacarose, nas temperaturas de 20 e $30^{\circ} \mathrm{C}$. Estes resultados podem estar associados ao fato de que a sacarose pode atuar como fonte de carbono e proteção adicional para as células de Saccharomyces cerevisiae (Tabela 2).

Tabela 2. Porcentagem de conversão (\%c) do acetoacetato de etila em (S)-(+)-3-hidroxibutirato de etila nos sistemas com e sem sacarose, em hexano

\begin{tabular}{lcc}
\hline Sistemas & $\% \mathrm{c}\left(20^{\circ} \mathrm{C}\right)$ & $\% \mathrm{c}\left(30^{\circ} \mathrm{C}\right)$ \\
\hline FP/K10 & 73 & 56 \\
FP/K10/S & 93 & 95 \\
FP/K10/G & 79 & 52 \\
FP/K10/G/S & 100 & 100 \\
\hline
\end{tabular}

Tempo reacional: 24 horas

Constatou-se também que o maior tempo de permanência do FP não imobilizado em solventes orgânicos está relacionado a um aparecimento de produtos secundários, detectados pelos cromatogramas. Porém, para o sistema imobilizado, ou seja, FP/K10/G/S, houve uma maior resistência quanto à formação de subprodutos indesejáveis.

A redução estereosseletiva de $\alpha$-halocetofenonas é potencialmente um excelente processo para obtenção de haloidrinas quirais, que podem ser usadas como blocos de construção quirais para alguns produtos naturais e fármacos opticamente ativos ${ }^{32}$. A biorredução da $\alpha$-cloroacetofenona tem sido realizada com FP em meio aquoso ${ }^{30,32,33}$. Neste trabalho, esta reação foi realizada em meio orgânico (Esquema 3).

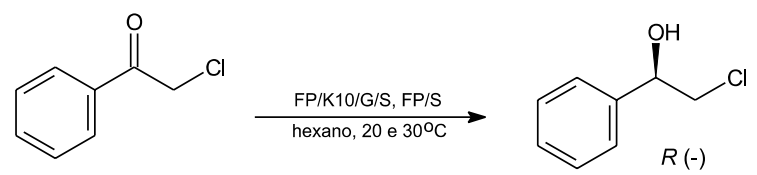

\section{Esquema 3}

Os dados de \%c e ee (\%) para formação do (R)-(-)-2-cloro-1feniletanol estão na Tabela 3.

A Tabela 3 demonstra que os valores de ee para o sistema FP/ K10/G/S (ee 73-79) foram sempre maiores que para FP/S (ee 55$60 \%$ ), independente do tempo e da temperatura. Os dados de \%c usando o sistema FP/K10/G/S foram menores que para FP/S. Estes resultados provavelmente mostram a maior dificuldade de difusão do reagente e do produto, no meio reacional, causada pela gelatina (G) e o K10. 
Tabela 3. Porcentagem de conversão (\%c) da $\alpha$-cloroacetofenona em $R$-(-)-2-cloro-1-feniletanol e os valores de ee (\%) obtidos em diferentes condições experimentais

\begin{tabular}{lcccccc}
\hline Sistemas & \multicolumn{2}{c}{ ee $\%^{\mathrm{a}}(\% \mathrm{c})^{\mathrm{b}} 24 \mathrm{~h}$} & \multicolumn{2}{c}{ ee $\% \mathrm{a}(\% \mathrm{c})^{\mathrm{b}} 48 \mathrm{~h}$} & \multicolumn{2}{c}{ ee $\%^{\mathrm{a}}(\% \mathrm{c})^{\mathrm{b}} 72 \mathrm{~h}$} \\
& $20{ }^{\circ} \mathrm{C}$ & $30{ }^{\circ} \mathrm{C}$ & $20{ }^{\circ} \mathrm{C}$ & $30{ }^{\circ} \mathrm{C}$ & $20{ }^{\circ} \mathrm{C}$ & $36(35)$ \\
\hline FP/S & $60(30)$ & $56(19)$ & $56(26)$ & $55(39)$ & $56(26)$ & $60(35)$ \\
FP/K10/G/S & $77(10)$ & $73(9)$ & $77(15)$ & $73(10)$ & $79(10)$ & $78(19)$ \\
\hline
\end{tabular}

${ }^{a}$ ee calculado pela \% de área (CG quiral).

${ }^{\mathrm{b}}$ determinados por $\mathrm{RMN}{ }^{1} \mathrm{H}$.

Foram realizados testes para verificar a ocorrência de inversão de configuração ao reutilizar estes sistemas nestas condições experimentais, considerando que isto ocorre em meio aquoso ${ }^{30}$. Entretanto, observou-se que não houve a inversão de configuração do $(R)$-(-)-2-cloro-1-feniletanol quando os sistemas foram reutilizados, e que a $\%$ c foi menor que 5\%. Este resultado mostra que o sistema de proteção FP/K10/G/S, para a parede celular, ainda não foi eficiente quando um substrato tóxico como a $\alpha$-cloroacetofenona foi utilizado em hexano, sugerindo a desativação das oxido-redutases.

\section{CONCLUSÕES}

O sistema FP/K10/G/S foi o que melhor protegeu as células na reação modelo, produziu menos subprodutos e manteve-se com atividade (ee $>99 \%$ ) até a quarta reutilização com uma porcentagem de conversão de acetoacetato de etila para o $(S)-(+)$-3-hidroxibutanoato (ee $>99 \%$ ) de etila de $19 \%$ a $20^{\circ} \mathrm{C}$.

A metodologia estudada para a proteção das células de Saccharomyces cerevisiae do meio reacional, mostrou-se também bastante eficiente na obtenção de produtos enantiomericamente puros como o $(R)$-(-)-2-cloro-1-feniletanol (ee $78 \%, 72 \mathrm{~h}$ a $\left.30^{\circ} \mathrm{C}\right)$. Uma grande vantagem deste método, está na facilidade de separação do produto desejado do meio reacional. Entretanto, a dificuldade de difusão dos reagentes e produtos pode levar à formação de produtos com baixos valores de \%c.

O método é adequado para ser empregado em reações de redução enantiosseletivas em laboratórios de química orgânica.

\section{AGRADECIMENTOS}

Ao DQ-UFSC, IQ-UNICAMP e CNPq pelo suporte financeiro e bolsas concedidas (SPM, SPZ e MGN) e ao Dr. A. C. Siani (FIOCRUZ) pelas sugestões e revisão do manuscrito.

\section{REFERÊNCIAS}

1. Bon, E. P. S.; Pereira Jr., N.; Tecnologia Enzimática; Fundação Biblioteca Nacional; Rio de Janeiro, RJ, 1999, p. 113.

2. Santaniello, E.; Ferraboschi, P; Grisenti, P.; Manzocchi, A.; Chem. Rev. 1992, 92, 1071 .

3. Roberts, S. M.; Turner, N. J.; Willetts, J.; Turner, M. K.; Introduction to Biocatalysis using Enzymes and Micro-organisms, Cambridge University Press: New York; 1995, p. 195.

4. Hudlicky, T.; Gonzalez, D.; Gibson, D. T.; Aldrichimica Acta 1999, 32, 35 .

5. Duran, N.; Conti, R. De; Rodrigues, J. A. R.; Bol. Soc. Chil. Quim. 2000, $45,109$.

6. Stewart, J. D.; Curr. Opin. Biotechnol. 2000, 11, 363.
7. Stanley, M. R.; J. Chem. Educ. 2000, 77, 344.

8. Rotthaus, O.; Krüger, D.; Demuth, M.; Schaffner, K.; Tetrahedron 1997, 53, 935.

9. Hudlicky, T.; Gonzalez, D.; Gibson, D. T.; Aldrichimica Acta 1999, 32 , 35.

10. Fernadez-Lafuente, R.; Armisén, P.; Sabuquillo, P.; Fernández-Lorente, G.; Guisán, J. M.; Chem. Phys. Lipids 1998, 93, 185.

11. Narvátil, M.; Sturdik, E.; Biologia 1999, 54, 635.

12. D’Arrigo, P.; Fantoni, G. P.; Servi, S.; Strinti, A.; Tetrahedron: Asymmetry 1997, 8, 2375.

13. Hayakawa, R.; Nozawa, K.; Shimizu, M.; Fujisawa, T.; Tetrahedron Lett. 1998, 39, 67 .

14. Pereira, R. S.; Crit. Rev. Biotechnol. 1998, 18, 25.

15. Dahl, A. C.; Madsen, J. O.; Tetrahedron: Asymmetry 1998, 6, 4395.

16. Bekatorou, A.; Koutinas, A. A.; Kaliafas, A.; Kanellaki, M.; Process Biochem. 2001, 36, 549 .

17. Grunwald, P.; Biochem. Educ. 2000, 28, 96.

18. Nakamura, K.; Kondo, S.; Kawai, Y.; Ohno, A.; Tetrahedron Lett. 1991, $32,7075$.

19. León, R.; Fernandes, P.; Pinheiro, H. M.; Cabral, J. M.; Enzyme Microb. Technol. 1998, 23, 483.

20. Jayasinghe, L. Y.; Kodituwakku, D.; Smallridge, A. J.; Trewhella, M. A.; Bull. Chem. Soc. Jpn. 1994, 67, 2528.

21. Nakamura, K.; Kondo, S.; Kawai, Y.; Ohno, A.; Bull. Chem. Soc. Jpn. 1993, 66, 2738.

22. Faber, K.; Biotransformations in Organic Chemistry, Springer-Verlag: Berlin 1997, p.p 402.

23. Medson, C.; Smallridge, A. J.; Trewhella, M. A.; Tetrahedron: Asymmetry 1997, 8, 1049.

24. Kanda, T.; Miyata, N.; Fukui, T.; Kawamoto, T.; Tanaka, A.; Appl. Microbiol. Biotechnol. 1998, 49, 377.

25. Medson, C.; Smallridge, A. J.; Trewhella, M. A.; J. Mol. Catal. B: Enzym. 2001, 11, 897 .

26. Athanasiou, N.; Smallridge, A. J.; Trewhella, M. A.; J. Mol. Catal. B: Enzym. 2001, 11, 893.

27. Dumanski, P. G.; Florey, P.; Knettig, M.; Smallridge, A. J.; Trewhella, M. A.; J. Mol. Catal. B: Enzym. 2001, 11, 905.

28. Furniss, B. S.; Hannaford, A. J.; Rogers, V.; Smith, P. W. G.; Tatchell, A. R.; Vogel's Textbook of Practical Organic Chemistry, 4a ed., Longman Group Limited: New York, 1978, p. 353.

29. Handbook of Chemistry and Physics, CRC Press: Boca Raton, 1979.

30. Sorrilha, A. E. P. M.; Marques, M.; Joekes, I.; Moran, P. J. S.; Rodrigues, J. A. R.; Bioorg. Med. Chem. Lett. 1992, 2, 191; Moran, P. J. S.; Rodrigues, J. A. R.; Joekes, I.; Brenelli, E. C. S.; Leite, R. A.; Biocatalysis 1994, 9, 321.

31. Wendhausen, R. Jr.; Moran, P. J. S. ; Joekes, I. ; Rodrigues, J. A. R.; J. Mol. Catal. B: Enzym. 1998, 5, 69.

32. Brenelli, E. C. S.; Carvalho, M.; Okubo, M. T.; Marques, M.; Moran, P. J. S.; Rodrigues, J. A. R.; Indian J. Chem. 1992, 31B, 821; Barbieri, C.; Bossi, L.; D’Arrigo, P.; Fantoni, G. P.; Servi, S.; J. Mol. Catal. B: Enzym. 2001, 11,415 .

33. Carvalho, M.; Okamoto, M. T.; Moran, P. J. S.; Rodrigues, J. A. R.; Tetrahedron 1991, 47, 2073; Aleixo, L. M.; Carvalho, M.; Moran, P. J. S.; Rodrigues, J. A. R.; Bioorg. Med. Chem. Lett. 1993, 3, 1637; Moran, P. J. S.; Rodrigues, J. A. R.; Carvalho, M.; Brenelli, E. C. S. de; Atualidades de Físico Química Orgânica, Ed. E. Humeres: Florianópolis, 1995, p. 499. 